\title{
EDITORIAL
}

\section{Consensus Science and the Peer Review}

\author{
Jorge R. Barrio \\ Editor-in-Chief \\ Department of Molecular and Medical Pharmacology, David Geffen UCLA School of Medicine, Los Angeles, CA, USA
}

I recently reviewed a lecture on science, politics, and consensus that Michael Crichton - a physician, producer, and writer-gave at the California Institute of Technology in Pasadena, CA, USA on January 17, 2003. I was struck by the timeliness of its content. I am quite certain that most of us have been - in one way or another-exposed to the concept (and consequences) of "consensus science." In fact, scientific reviewers of journal articles or grant applications - typically in biomedical research - may use the term (e.g., "....it is the consensus in the field...") often as a justification for shutting down ideas not associated with their beliefs.

I have always had a negative gut reaction to the concept of "consensus science." But Michael Crichton explains it best when he said:

I regard consensus science as an extremely pernicious development that ought to be stopped cold in its tracks. Historically, the claim of consensus has been the first refuge of scoundrels; it is a way to avoid debate by claiming that the matter is already settled. Whenever you hear the consensus of scientists agrees on something or other, reach for your wallet, because you're being had.

And he continues:

Let's be clear: the work of science has nothing whatever to do with consensus. Consensus is the business of politics. Science, on the contrary, requires only one investigator who happens to be right, which means that he or she has results that are verifiable by reference to the real world. In science consensus is irrelevant. What are relevant are reproducible results. The greatest scientists in history are great precisely because they broke with the consensus. There is no such thing as consensus science. If it's consensus, it isn't science. If it's science, it isn't consensus. Period.
It is indeed hard to disagree with Mr. Crichton. The historical track record of scientific consensus is nothing but dismal. Many examples can be cited, but there are some classical ones. Nicholas Copernicus and his follower, Galileo Galilei, experienced the effects of consensus when they advanced theories that planet Earth was not the center of the Universe. The sixteenth and seventeenth centuries were not the right time to go against established dogmas.

Today, the methods for exacting consensus have changed but the result could be the same: The death of the spirit. The use and abuse of "consensus science" is at least partially responsible for the current crisis in the scientific and medical peer review system. Although peer review may be considered one of the sacred pillars of the scientific edifice, it has been under fire for some time now because peer review controls access to publications and funding, thus bringing the problem into sharp focus.

On one extreme, some believe that the current peer review system "is a non-validated charade whose processes generate results little better than does chance" [1]. Responding to generalized concerns, the NIH has recently produced new rules for grant writing and reviews, mainly with the intent to stimulate formulation of new ideas, but in the end it is us who must forcefully strive for the honest debate of truthful facts for the benefit of all. It is our responsibility as scientists, physicians, reviewers, and/or editors to be alert and always remember that "...consensus is invoked only in situations where the science is not solid enough. Nobody says the consensus of scientists agrees that $\mathrm{E}=\mathrm{mc} 2$. Nobody says the consensus is that the sun is 93 million miles away. It would never occur to anyone to speak that way" (M. Crichton).

Open Access. This article is distributed under the terms of the Creative Commons Attribution Noncommercial License which permits any noncommercial use, distribution, and reproduction in any medium, provided the original author(s) and source are credited.

\section{References}

1. Horrobin DF (2001) Something rotten at the core of science? Trends Pharmacol Sci 22:51-52 